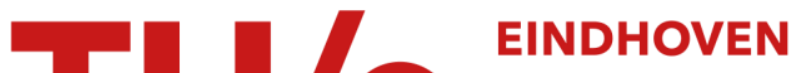 UNIVERSITY OF TECHNOLOGY
}

\section{Recent achievements in POF transmission}

\section{Citation for published version (APA):}

Tangdiongga, E., Shi, Y., Okonkwo, C. M., Van Den Boom, H. P. A., \& Koonen, A. M. J. (2012). Recent achievements in POF transmission. In 2012 38th European Conference and Exhibition on Optical Communications, ECOC 2012 (pp. Mo.2.G). [6705962] Optical Society of America (OSA). https://doi.org/10.1364/ECEOC.2012.Mo.2.G.1

DOI:

10.1364/ECEOC.2012.Mo.2.G.1

Document status and date:

Published: 01/12/2012

\section{Document Version:}

Accepted manuscript including changes made at the peer-review stage

\section{Please check the document version of this publication:}

- A submitted manuscript is the version of the article upon submission and before peer-review. There can be important differences between the submitted version and the official published version of record. People interested in the research are advised to contact the author for the final version of the publication, or visit the $\mathrm{DOI}$ to the publisher's website.

- The final author version and the galley proof are versions of the publication after peer review.

- The final published version features the final layout of the paper including the volume, issue and page numbers.

Link to publication

\section{General rights}

Copyright and moral rights for the publications made accessible in the public portal are retained by the authors and/or other copyright owners and it is a condition of accessing publications that users recognise and abide by the legal requirements associated with these rights.

- Users may download and print one copy of any publication from the public portal for the purpose of private study or research.

- You may not further distribute the material or use it for any profit-making activity or commercial gain

- You may freely distribute the URL identifying the publication in the public portal.

If the publication is distributed under the terms of Article 25fa of the Dutch Copyright Act, indicated by the "Taverne" license above, please follow below link for the End User Agreement:

www.tue.nl/taverne

Take down policy

If you believe that this document breaches copyright please contact us at:

openaccess@tue.nl

providing details and we will investigate your claim. 


\title{
Recent Achievements in POF Transmission
}

\author{
E. Tangdiongga, Y. Shi, C.M. Okonkwo, H.P.A. van den Boom, A.M.J. Koonen \\ COBRA Research Institute, Eindhoven University of Technology, P.O. Box 513, 5600 MB, Eindhoven, \\ The Netherlands, e.tangdiongga@tue.nl
}

\begin{abstract}
The potential for 'do-it-yourself' installation, easy maintenance, and high bending tolerance is driving the commercialization of large-core polymethylmetacrylate (PMMA) plastic optical fibres (POFs) for short-range multi-gigabit transmission capacities. Record transmission rates have been achieved, by using advanced modulation formats with simple intensity-modulation direct-detection systems with low-cost and eye-safe transceivers to enable transmission over 50-m POF links. In addition, results of transmitting high-capacity baseband signals together with wireless signals such as OFDM ultra-wide band transmitted over a single POF infrastructure are presented to highlight the key potential for POF-enabled delivery of both high-speed wired and wireless services.
\end{abstract}

\section{Introduction}

In comparison with silica fibres and CAT-5E, 1 $\mathrm{mm}$ core diameter polymethylmethacrylate (PMMA) plastic optical fibre (POF) has been shown as a cost-attractive cable medium ${ }^{1}$ for short-range communication thanks to its potential for simpler installation and less operational complexity hence reducing the system cost. The commercialization of largecore POFs for providing high-capacity transmission in excess of $1 \mathrm{Gbit} / \mathrm{s}$ has gathered pace for in-home networks. Whilst conventional standard A4a.2 step-index POF has been shown for gigabit transmission, grade-index (GI) POFs are more attractive for multi-Gigabit transmission rates. For such transmission goals, advanced modulation techniques are needed to narrow the bandwidth of high data rate signals, such as single-tone multi-level pulse amplitude modulation (PAM) and discrete multitone (DMT) techniques, resulting in dispersion-tolerant transmissions ${ }^{2}$. Moreover, to maximize the throughput per channel, a (fractional) quadrature amplitude modulation (QAM) scheme with DMT algorithm can be employed to achieve higher spectral efficiency and a significant data rate improvement when compared to the conventional DMT techniques. The development and commercialization of low-cost transceivers at visible wavelengths will enable a costeffective end-to-end solution.

Next to the baseband transmission, the capability of POFs in transporting multi-band orthogonal frequency division multiplexing (MBOFDM) ultra wide band (UWB) wireless services typically for in-home networks has been demonstrated recently ${ }^{3}$. To reduce maintenance and upgrades, a single home network is envisaged which integrates the delivery of wire-bound and wireless high-speed services. A preliminary study on the feasibility of large-core POFs in transporting multi-format signals was reported ${ }^{4}$.

To take into account the main options and best solutions available, this paper presents recent achievements of a multi-Gbit/s transmission over large-core GI-POF employing the DMT scheme, and a simultaneous transmission of baseband signals in DMT format and wireless signals in UWB format over 50-m long 1-mm core size GI-POF and an air link of less than $3 \mathrm{~m}$ by utilizing the available narrow system bandwidth.

\section{Multi-Gigabit Transmission}

DMT together with bit and power loading algorithm has been proposed for POF links to achieve high spectral efficiency, overcoming the bandwidth bottleneck in order to realize multi-gigabit transmissions. In comparison with conventional DMT technologies (power of $2^{\mathrm{N}}$ ), a novel $3 \times 2^{\mathrm{N}}-\mathrm{QAM}$ constellation scheme allows a finer granularity in the bit allocation, hence more efficient in using the available bandwidth. An improved achievable data rate is demonstrated

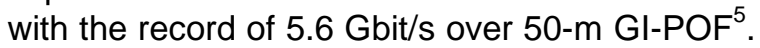
A VCSEL at $667 \mathrm{~nm}$ is used as the optical transmitter with an output power within the eyesafe regulation $(<0 \mathrm{dBm})$. The transmitter is followed by $50-\mathrm{m}$ GI-POF and a silicon avalanche photodetector (APD). The DMT signals were coded in Matlab and generated from an arbitrary waveform generator (AWG) whose output modulates the VCSEL. The received electrical signal is captured by a digital sampling scope (DPO) at $50 \mathrm{GSa} / \mathrm{s}$ with an 8-bit $A D C$ resolution. The available system bandwidth of the 50-m PMMA GI-POF link is $1.35 \mathrm{GHz}$, as shown in Fig. 1. 256 subcarriers are distributed beyond the 3-dB system bandwidth to $1.6 \mathrm{GHz}$ for both $2^{\mathrm{N}}$ and $3 \times 2^{\mathrm{N}}$ QAM constellations. One of the main advantages of DMT is its possibility to allocate the number of bits per subcarrier according to the corresponding signal-to-noise ratio (SNR) of the channel. To achieve optimal 


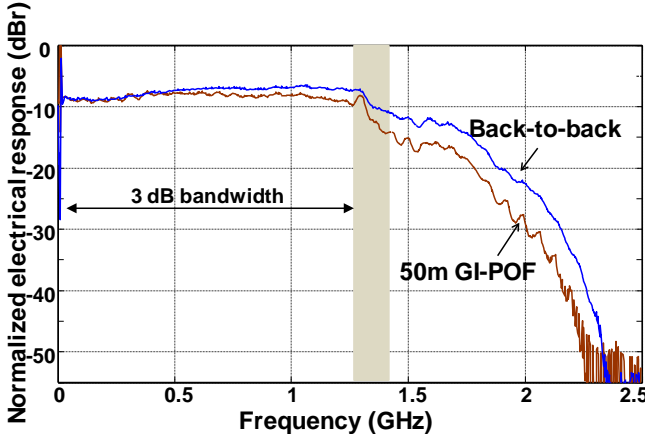

Fig. 1: Normalized system bandwidth for a 50-m PMMA GI-POF link.

bit allocation, a Chow's method is employed for the rate-adaptive bit loading algorithm here.

Fig. 2 shows the bit and power allocation per subcarrier when the bit-loading algorithm uses the QAM constellations of $2^{\mathrm{N}}$ and $3 \times 2^{\mathrm{N}}$ respectively. Note that in Fig. 2(a) the constellations allocated to the subcarriers range from 2-QAM to 32-QAM, when a finer granularity in the bit allocation of 0.5 bit is also involved. The power allocation exhibits a uniform power distribution (varying up to $1.5 \mathrm{~dB}$ ) among the subcarriers, as shown in Fig. 2(b). Fig. 3 shows two examples of received $3 \times 2^{\mathrm{N}}$-QAM constellations, in particular 24-QAM $\left(3 \times 2^{3}\right)$ (left) and 6-QAM $\left(3 \times 2^{1}\right)$ (right). The clearly distinguishable constellation points indicate that the received signal quality is reasonably good after the equalization step. The total bit-rate achieved is $5.6 \mathrm{Gbit} / \mathrm{s}$ with a bit error rate (BER) below $10^{-3}$. Compared to the

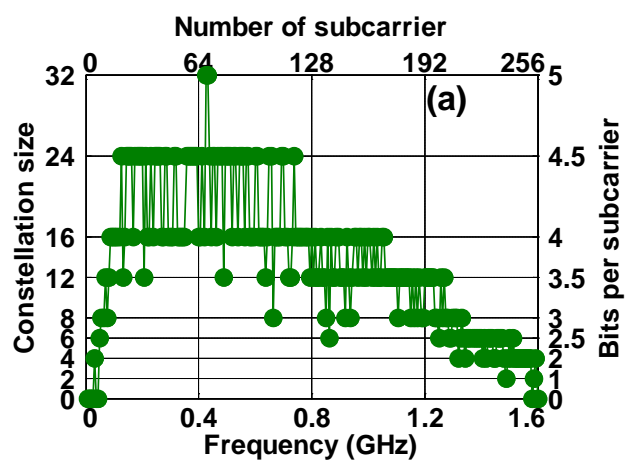

(a)

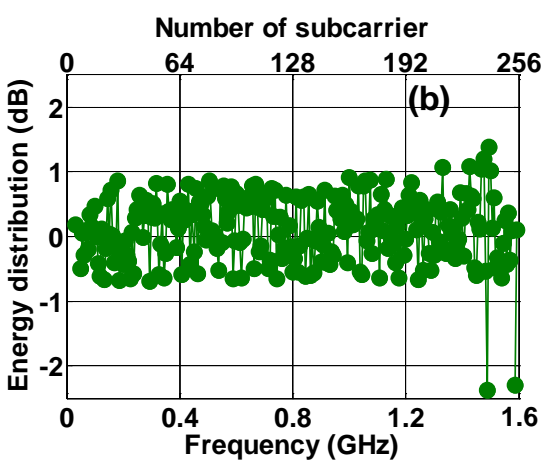

(b)

Fig. 2 Bits (a) and power (b) allocation of the DMT signal with bit-loading algorithm and involving both $2^{N}$ and $3 \times 2^{N}-$ QAM constellation formats.
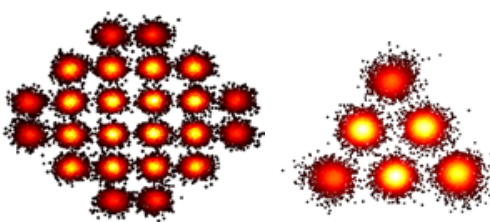

Fig. 3. 24-QAM (left) and 6-QAM (right) received constellations.

conventional DMT approach, a percentage gain of $12 \%$ in maximum achievable bit-rate can be noticed $^{5}$.

\section{Converged Wired and Wireless over POF}

To fully employ POF links in a realistic in-home scenario, converged wired and wireless transmission over a single POF is attractive to be explored ${ }^{6}$. By downshifting the spectrum of an OFDM UWB radio signal to the intermediate frequency (IF) band, we have realized successful simultaneous transmission of a $3 \times 2{ }^{\mathrm{N}}$ QAM DMT signal at $3 \mathrm{Gbit} / \mathrm{s}$ and a WiMediacompliant OFDM UWB signal at $480 \mathrm{Mbit} / \mathrm{s}$ including $<3 \mathrm{~m}$ air link with an error vector magnitude (EVM) less than 15\%. Two signals fit nicely within in the bandwidth of a POF link.

The experimental setup is shown in Fig. 4. A baseband DMT signal and a $528 \mathrm{MHz}$ RF UWB signal, with the centre frequency of $3.96 \mathrm{GHz}$ (TFC6, $3.696-4.224 \mathrm{GHz}$ ) at $480 \mathrm{Mbit} / \mathrm{s}$ are generated by an AWG with two channel outputs. The available system bandwidth is the same as Fig. 1. The transmitted signals are spectrally located within this bandwidth. DMT and IF UWB signals are located from $\mathrm{DC}$ to $800 \mathrm{MHz}$ and from $0.836 \mathrm{GHz}$ to $1.364 \mathrm{GHz}$, respectively, as shown in Fig. 4 (inset). The optical transcevier

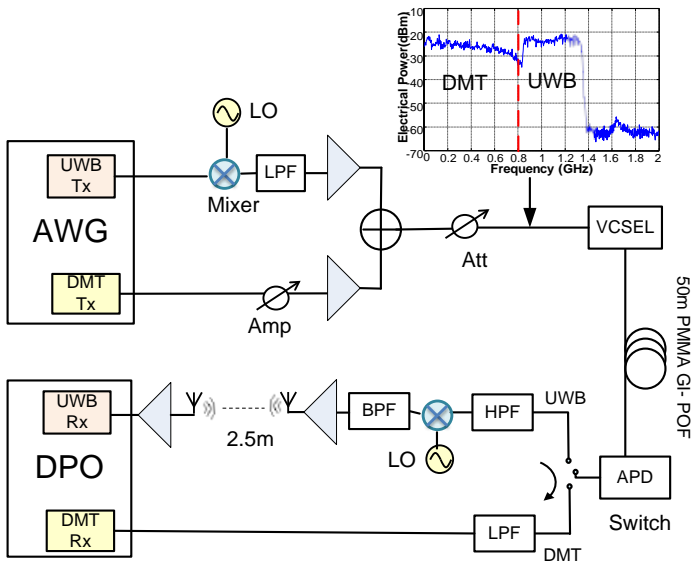

Fig. 4: Expremental setup of converged transport of wired DMT and wireless UWB signals over a 50-m POF link. Inset: spectral allocation of DMT and UWB in the available bandwidth.

(VCSEL and APD) and the 50-m GI-POF link are with the same operation condition as in the previous section. After the photo detection, the DMT signal is captured by a DPO with a sampling rate of $50 \mathrm{GSa} / \mathrm{s}$ for off-line 
processing. On the other hand, the UWB signal is restored to its original frequency before being radiated wirelessly. The UWB signal is transmitted using an omnidirectional patch antenna (gain: $0 \mathrm{dBi}$ ) over a wireless channel of $<3 \mathrm{~m}$. An additional omnidirectional antenna is configured as the mobile unit to receive UWB signals. The DPO is used to evaluate the quality of the received UWB signals at different transmission points.
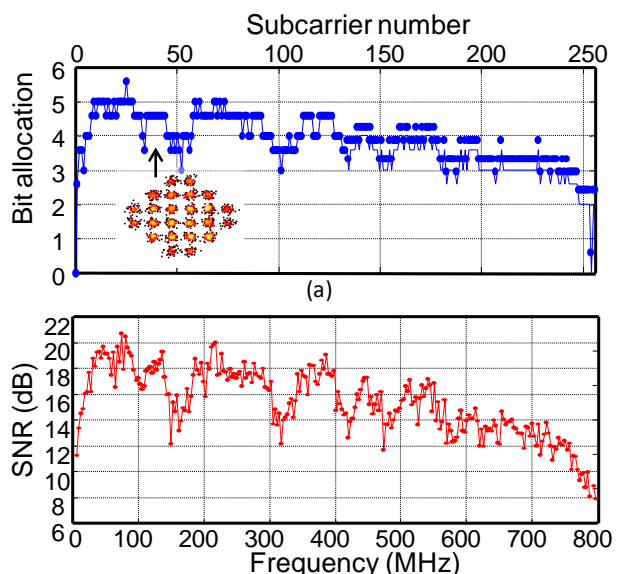

(b)

Fig. 5 DMT transmission performance with UWB coexistence: (a) bit allocation, (b) SNR distribution. Inset of (a): $24\left(3 \times 2^{3}\right)$ QAM for subcarrier index 36-45.

Fig. 5 presents the detailed measurement results for the DMT signal using bit-loading algorithm. The maximum bit allocation value is 5 bits per carrier and a fractional number $\mathrm{N}+1.5$ of bits per symbol is supported, which means 6QAM, 12-QAM and 24-QAM are also employed to achieve a finer granularity in bit allocation. The bit allocations result in a discrete mapping of the SNR to the sub-carriers index and frequency, as shown in Fig. 5(b). An example of demodulated signal constellation diagrams is

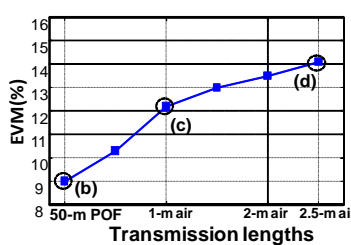

(a)

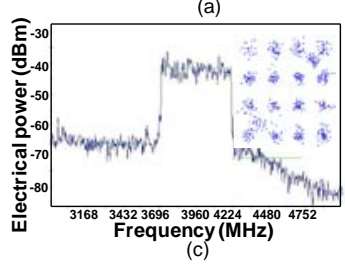

Fig. 6 Received UWB signals evaluation: (a) EVM performance, (b)-(d) spectrum and constellations of UWB signals: (b) 50-m POF, (c) 50-m POF and 1-m wireless link, (d) $50-\mathrm{m}$ POF and $2.5-\mathrm{m}$ wireless link shown as the inset of Fig. 5(a), 4.5 bit corresponding to 24-QAM, is used for the 36th to 45th sub-carrier.

We kept the DMT signals running with their parameters optimized and evaluated the performance of spectrum and EVM for UWB signals after 50-m POF transmission, including 1-m, 2-m or near 3-m wireless links. As depicted in Fig. 6(a), the EVM values change from 9\% to $14.1 \%$ with an increasing transmission distance. However, even for the worst case of 50-m POF link plus <3-m wireless link, the EVM is below $15 \%$. Spectrum and constellations at different evaluation points are shown in Fig. 6(b) - (d). We can observe that the signal after the optical link maintains high quality with only a small penalty. The main degradation to UWB signals is from air transmission which introduces $20 \mathrm{~dB}$ SNR and 5\% EVM degradations. This is mainly due to the impact of multipath fading and other wireless interferences. It is worth to note that larger optical and wireless link can be obtained by using higher optical launch power and directive antennas.

\section{Conclusions}

We have presented an overview of state-of-the art technologies for multi-Giga baseband signal and a converged baseband and RF signals transmission over $1 \mathrm{~mm}$ core diameter $50-\mathrm{m}$ PMMA POFs. The achieved results demonstrate a significant progress for short-range in-home optical communications. Advanced modulations (fractional DMT, frequency-shifted multiband OFDM UWB) together with the state-of-the-art optical transceivers, can realize high data rates over the bandwidth limited POF links. The feasibility of the convergence of high-capacity wired and wireless services within a POF network validates the idea of using $1 \mathrm{~mm}$ core size POF link as a supporting infrastructure for optical in-home networks.

\section{Acknowledgements}

This work was supported by the EC FP7 research projects ALPHA, POF-PLUS and EURO-FOS.

\section{References}

[1] Koonen et al., Opt. Express, 19, B399 (2011)

[2] Randel et al., J. Lightwave Technol., 16, 1280 (2010).

[3] Shi et al., Proc. OFC'11, OWB5

[4] Visani et. al., Electron. Lett., 47, 203(2011)

[5]Visani et. al., Photon. Technol. Lett., 23, 768 (2011)

[6] Shi et al., Proc. ECOC'12, Tu.3.C. 